\title{
Hubungan Umur, Pendidikan dan Pekerjaan Ibu dengan Akseptor KB Implant di Puskesmas Sri Gunung Kabupaten Musi Banyuasin Tahun 2019
}

\author{
Paula Citra Hakim $\mathrm{S}^{1^{*}}$, Siti Aisyah ${ }^{2}$, Eka Afrika ${ }^{3}$ \\ ${ }^{1}$ Puskesmas Srigunung Kabupaten Musi Banyuasin \\ ${ }^{2}$ Program Studi DIV Kebidanan Fakultas Kebidanan dan Keperawatan, Universitas Kader Bangsa Palembang \\ ${ }^{3}$ Fakultas Kebidanan dan Keperawatan, Universitas Kader Bangsa Palembang \\ "Correspondence email: paula.hakimsimatupang @ gmail.com
}

\begin{abstract}
Abstrak. Jumlah akseptor KB Implant saat ini masih sangat rendah karena minimnya pengetahuan akseptor tentang kualitas KB Implant yang lebih efektif, diketahui bahwa program keluarga berencana mempunyai peranan sangat penting dalam menekan pertumbuhan penduduk, terutama pencegahan kematian dan kesakitan ibu, Implant adalah alat kontrasepsi yang disusupkan di bawah kulit, biasanya dipasang di lengan atas. Penelitian ini bertujuan untuk mengetahui hubungan umur, pendidikan dan pekerjaan ibu dengan akseptor KB Implant di Puskesmas Srigunung Kabupaten Musi Banyuasin tahun 2019. Tujuan dalam penelitian ini untuk mengetahui hubungan umur, pendidikan dan pekerjaan ibu dengan akseptor KB implant di Puskesmas Srigunung Tahun 2019. Penelitian ini menggunakan survey analitik dengan pendekatan cross Sectional. Populasi penelitian ini adalah semua wanita usia subur yang merupakan peserta KB aktif yang berkunjung di wilayah kerja Puskesmas Srigunung Kabupaten Musi Banyuasin. Sample dari penelitian ini sebanyak 97 responden yang diambil secara acak sistematis dengan cara membagi jumlah sampel yang diinginkan dengan menggunakan metode random sampling. Berdasarkan analisis didapatkan bahwa terdapat hubungan yang signifikan antara umur ( $\rho$ value 0,000$)$, Pendidikan ( $\rho$ value 0,000$)$, pekerjaan ibu $(\rho$ value 0,000$)$ dengan Akseptor KB Implant di Puskesmas Sri Gunung Kabupaten Musi Banyuasin Tahun 2019. Kesimpulan dalam penelitian ini dapat diketahui bahwa terdapat hubungan antara umur, pendidikan dan pekerjaan ibu dengan akseptor KB Implant di Puskesmas Sri Gunung Kabupaten Musi Banyuasin Tahun 2019.
\end{abstract}

Kata kunci: Implant; Pekerjaan; Pendidikan; Umur

\begin{abstract}
The number of acceptors for family planning implants is currently still very low due to the lack of knowledge of acceptors about the quality of family planning implants that are more effective, it is known that family planning programs have a very important role in suppressing population growth, especially prevention of maternal death and morbidity, implants are contraceptives that are inserted under skin, usually attached to the upper arm. This study aims to determine the relationship between age, education and work of mothers with family planning implant acceptors at the Srigunung Health Center, Musi Banyuasin Regency in 2019. The purpose of this study is to determine the relationship between age, education and occupation of mothers with implant family planning acceptors at Srigunung Health Center in 2019. This study using an analytic survey with a cross sectional approach. The population of this study were all women of childbearing age who were active family planning participants visiting the Srigunung Public Health Center, Musi Banyuasin District. The sample of this study were 97 respondents who were taken systematically randomly by dividing the number of samples desired by using the random sampling method. Based on the analysis, it was found that there was a significant relationship between age ( $\rho$ value 0,000), education ( $\rho$ value 0,000), maternal occupation ( $\rho$ value 0,000) with family planning acceptors at the Sri Gunung Puskesmas, Musi Banyuasin Regency in 2019. The conclusions in this study can be seen that there is a relationship between age, education and occupation of mothers with family planning implant acceptors at the Sri Gunung Puskesmas, Musi Banyuasin Regency in 2019.
\end{abstract}

Keywords: Age; Education; Implant; Profession

\section{PENDAHULUAN}

Menurut Word Health Organization (WHO) Keluarga Berencana adalah tindakan yang membentuk individu atau pasangan suami istri untuk mendapatkan objektif-objektif tertentu. Menghindari kelahiran yang tidak diinginkan, mendapatkan kelahiran yang memang diinginkan, mengatur interval diantara kehamilan, mengontrol waktu saat kelahiran, menentukan jumlah anak dalam keluarga (Suratun, S, 2008).

Implant adalah alat metode kontrasepsi hormonal yang efektif, tidak permanen dan dapat mencegah terjadinya kehamilan antara tiga hingga lima tahun. Apabila dibandingkan dengan alat kontrasepsi lain, kontrasepsi implant merupakan alat kontrasepsi yang sama-sama mempunyai efektivitas jangka panjang seperti IUD atau spiral. Dapat dilihat bahwa implant merupakan alat kontrasepsi yang lebih efektif serta lebih mudah dalam proses pemasangannya. Namun belakangan ini alat kontrasepsi IUD mempunyai kelemahan yaitu dapat terjadi perubahan lokasi dan translokasi atau keluar dari rahim sehingga masih menimbulkan terjadinya kehamilan. Implant mempunyai tingkat kegagalan yang lebih sedikit dibandingkan IUD. Apabila dipasang dengan benar, metode kontrasepsi implant memiliki efektivitas sampai $99 \%$ dengan tingkat kegagalan hanya 0,05 dari 100 wanita yang memakainya (Kusmiwiyati, A. 2018). 
Saat ini penduduk Indonesia berjumlah kurang lebih 228 juta jiwa. Dengan pertumbuhan penduduk 1,64\% dan Total Fertility Rate (TFR) 2,6. Dari segi kualitas jumlah penduduk Indonesia cukup besar tetapi dari sisi kualitas melalui Indeks Pembangunan Manusia (IPM) kondisi Indonesia sangat memprihatinkan karena dari 117 negara, Indonesia di posisi 180, tingginya laju pertumbuhan yang tidak diiringi peningkatan kualitas penduduk ini terus dilakukan upaya penanganan yaitu dengan program keluarga berencana (Handayani, 2010).

Berdasarkan data dan informasi profil kesehatan Indonesia presentase Akseptor $\mathrm{KB}$ menurut metode kontrasepsi tahun 2017, dengan jumlah PUS sebanyak 1.217.559 jiwa, jumlah akseptor MOP sebanyak 2112 (0,26 \%), MOW sebanyak 6428 (0,79\%), Implant sebanyak 101.388 (12,44\%), IUD sebanyak 16.235 (2 $\%)$. Tahun 2018 PUS sebanyak 1.233.883 jiwa, MOP sebanyak $2107(0,26 \%)$, MOW sebanyak $6425(0,78$ $\%)$, Implant sebanyak 104.136 (12,7 \%), IUD sebanyak 16,442 (2,01\%) (Kemenkes RI, 2017).

Usia ibu PUS diatas 35 tahun dianjurkan menggunakan kontrasepsi yang efektif sangat tinggi yaitu KB nonhormonal. Sehingga dapat disimpulkan bahwa usia mempunyai hubungan yang positif dengan pemilihan jenis alat kontrasepsi dimana seiring tingginya tingkat kematangan atau usia responden akan diikuti kenaikan dalam pemilihan jenis alat kontrasepsi nonhormonal (Saifuddin, 2010).

Jumlah akseptor KB Implant masih sangat rendah karena minimnya pengetahuan akseptor tentang kualitas KB Implant yang lebih efektif, diketahui bahwa program keluarga berencana mempunyai peranan sangat penting dalam menekan pertumbuhan penduduk, terutama pencegahan kematian dan kesakitan ibu. Faktor yang mempengaruhi Pemakaian Alat Kontrasepsi Implant yaitu tingkat pendidikan, umur, pengetahuan, pekerjaan, Akses Kefasilitas Pelayanan, dan Dukungan Suami (Prawirohardjo, 2008).

Berdasarkan teori bahwa pendidikan formal sangat besar pengaruhnya terhadap pengetahuan seseorang, bila seseorang berpendidikan tinggi maka akan memiliki pengetahuan yang tinggi pula sebaliknya jika seseorang memiliki pendidikan rendah akan memiliki pengetahuan yang rendah dan akan mempengaruhi dalam memahami sesuatu hal. Akan tetapi perlu ditekankan bahwa seseorang yang berpendidikan rendah tidak mutlak berpengetahuan rendah pula diman pengetahuan ataupun informasi dapat diperoleh bukan hanya secara formal tetapi juga non formal (Budiman, A. R, 2013).

Status ketenagakerjaan istri berpengaruh terhadap pemakaian kontrasepsi, istri yang bekerja memiliki waktu yang lebih sedikit mengurus anak dibandingkan dengan istri yang tidak bekerja, oleh karena itu istri yang bekerja lebih banyak menggunakan kontrasepsi dari pada istri yang tidak bekerja (Statistik, B. P., \& BKKBN, K. 2007).

\section{METODE}

Penelitian ini adalah bersifat kuantitatif dengan pendekatan cross sectional, yang bertujuan untuk mengetahui hubungan variabel independen yaitu umur, pendidikan dan pekerjaan ibu dengan variabel dependen yaitu Akseptor KB Implant.

Populasi dalam penelitian ini adalah semua wanita usia subur yang merupakan peserta KB aktif yang berkunjung di Wilayah Kerja Puskesmas Sri Gunung Kabupaten Musi Banyuasin Tahun 2019 yang diperkirakan berjumlah 3.638 orang.

Sample penelitian diambil dengan menggunakan random sampling dengan teknik systematic random sampling atau pengambilan sample secara acak sistematis dengan cara membagi jumlah atau anggota populasi dengan perkiraan sample yang diinginkan, hasilnya interval sample. Sample pada pada penelitian ini adalah seluruh dari wanita usia subur yang merupakan peserta KB aktif yang berkunjung di wilayah kerja Puskesmas Srigunung Kabupaten Musi Banyuasin Tahun 2019. dengan jumlah sample 3.683 orang. Penelitian ini telah dilaksanakan pada bulan Juni s/d Agustus Tahun 2020.

\section{HASIL DAN PEMBAHASAN}

\section{Analisis Univariat}

Hasil analisis univariat kejadian persalinan perterm tampak pada tabel 1 .

Tabel 1. Distribusi Frekuensi dan Persentase Responden Berdasarkan Akseptor KB Implant di Puskesmas Sri Gunung Tahun 2019

\begin{tabular}{lcc}
\hline Akseptor KB Implant & Frekuensi (f) & Persentase \% \\
\hline Ya & 43 & 44,3 \\
Tidak & 54 & 55,7 \\
Jumlah & 97 & 100 \\
\hline
\end{tabular}

Tabel 1 menunjukkan lebih dari separuh wanita usia subur yang tidak menggunakan KB Implant (55,7 \%) sedangkan wanita usia subur yang menggunakan KB Implant $(44,3)$.

Tabel 2. Distribusi Frekuensi dan Persentase Responden Berdasarkan Umur di Puskesmas Sri Gunung Tahun 2019

\begin{tabular}{lcc}
\hline \multicolumn{1}{c}{ Umur } & Frekuensi (f) & Persentase \% \\
\hline Berisiko & 58 & 59,8 \\
Tidak Beresiko & 39 & 40,2 \\
Jumlah & 97 & 100 \\
\hline
\end{tabular}

Tabel 2 menunjukkan lebih dari separuh wanita yang umurnya beresiko $(59,8 \%)$, sedangkan wanita yang umurnya tidak beresiko $(40,2 \%)$. 
Paula Citra Hakim S, Siti Aisyah dan Eka Afrika, Hubungan Umur, Pendidikan dan Pekerjaan Ibu dengan Akseptor KB Implant di Puskesmas Sri Gunung Kabupaten Musi Banyuasin Tahun 2019

Tabel 3. Distribusi Frekuensi dan Persentase Responden Berdasarkan Pendidikan di Puskesmas Sri Gunung Tahun 2019

\begin{tabular}{lcc}
\hline Pendidikan & Frekuensi (f) & Persentase \% \\
\hline Tinggi & 62 & 63,9 \\
Rendah & 35 & 36,1 \\
Jumlah & 97 & 100 \\
\hline
\end{tabular}

Tabel 3 menunjukkan lebih dari separuh wanita usia subur yang pendidikannya tinggi (63,9 \%), sedangkan wanita usia subur yang pendidikannya rendah $(36,1 \%)$.
Tabel 4. Distribusi Frekuensi dan Persentase Responden Berdasarkan Pekerjaan Ibu di Puskesmas Sri Gunung Tahun 2019

\begin{tabular}{lcc}
\hline \multicolumn{1}{c}{ Pekerjaan Ibu } & Frekuensi (f) & Persentase\% \\
\hline Ya & 68 & 70,1 \\
Tidak & 29 & 29,9 \\
Jumlah & 97 & 100 \\
\hline
\end{tabular}

Tabel 4 menunjukkan lebih dari separuh wanita yang bekerja $(70,1 \%)$, sedangkan wanita yang tidak bekerja $(29,9 \%)$.

\section{Analisis Bivariat}

Hasil analisis bivariat hubungan hubungan umur dengan akseptor kb implant, dapat dilihat pada tabel 5.

Tabel 5. Hubungan umur dengan Akseptor KB Implant di Puskesmas Sri Gunung Tahun 2019

\begin{tabular}{|c|c|c|c|c|c|c|c|c|}
\hline \multirow{3}{*}{ Umur } & \multicolumn{4}{|c|}{ Akseptor KB Implant } & \multirow{2}{*}{\multicolumn{2}{|c|}{ Jumlah }} & \multirow{3}{*}{$\begin{array}{c}P \\
\text { Value }\end{array}$} & \multirow{3}{*}{$\mathbf{O R}$} \\
\hline & \multicolumn{2}{|c|}{ Ya } & \multicolumn{2}{|c|}{ Tidak } & & & & \\
\hline & f & $\%$ & f & $\%$ & f & $\%$ & & \\
\hline Berisiko & 35 & 60,3 & 23 & 39,7 & 58 & 100,0 & 0,000 & 5.897 \\
\hline Tidak Beresiko & 8 & 20,5 & 31 & 79,5 & 39 & 100,0 & & $(2.307-15.074)$ \\
\hline Jumlah & 43 & & 54 & & 97 & & & \\
\hline
\end{tabular}

Tabel 5 menunjukkan persentase KB Implant lebih tinggi pada ibu umur beresiko dibandingkan dengan ibu umur tidak beresiko (60,3\%). Hasil uji chi square didapatkan $\mathrm{p}$-value $<\alpha$ 0,05, artinya ada hubungan yang bermakna antara frekuensi umur dengan Akseptor KB Implant. OR yang didapat yaitu 5.897, artinya ibu yang umurnya beresiko berpeluang 5,897 kali menggunakan kontrasepsi Implant dibandingkan ibu dengan umur tidak berisiko (OR : 2.307 - 15.074).

Hubungan frekuensi pendidikan dengan akseptor $\mathrm{kb}$ implant dapat dilihat pada tabel 6.

Tabel 6. Hubungan frekuensi pendidikan dengan akseptor kb implant di Puskesmas Sri Gunung Tahun 2019

\begin{tabular}{|c|c|c|c|c|c|c|c|c|}
\hline \multirow{3}{*}{ Pendidikan } & \multicolumn{4}{|c|}{ Akseptor KB Implant } & \multirow{2}{*}{\multicolumn{2}{|c|}{ Jumlah }} & \multirow{3}{*}{$\begin{array}{c}P \\
\text { Value }\end{array}$} & \multirow{3}{*}{ OR } \\
\hline & \multicolumn{2}{|c|}{ Ya } & \multicolumn{2}{|c|}{ Tidak } & & & & \\
\hline & $\mathbf{f}$ & $\%$ & $\mathbf{f}$ & $\%$ & $\mathbf{f}$ & $\%$ & & \\
\hline Tinggi & 38 & 61,3 & 24 & 38,7 & 62 & 100,0 & 0,000 & 9.500 \\
\hline Rendah & 5 & 14,3 & 30 & 85,7 & 35 & 100,0 & & $(3.240-27.859)$ \\
\hline Jumlah & 43 & & 54 & & 97 & & & \\
\hline
\end{tabular}

Tabel 6 menunjukkan persentase KB Implant lebih tinggi pada ibu yang berpendidikan tinggi dibandingkan ibu yang berpendidikan rendah $(61,3 \%)$. Hasil uji chi square didapatkan p-value $<\alpha 0,05$, artinya ada hubungan yang bermakna antara frekuensi pendidikan dengan Akseptor KB Implant. OR yang didapat yaitu 9.500, artinya ibu berpendidikan tinggi mempunyai peluang 9,500 kali menggunakan kontrasepsi Implant dibandingkan ibu yang berpendidikan rendah (OR : 3.240 - 27.859).

Hubungan frekuensi pekerjaan ibu dengan akseptor kb implant dapat dilihat pada tabel 7 .

Tabel 7. Hubungan frekuensi pekerjaan ibu dengan akseptor kb implant di Puskesmas Sri Gunung Tahun 2019

\begin{tabular}{|c|c|c|c|c|c|c|c|c|}
\hline \multirow{3}{*}{ Pekerjaan ibu } & \multicolumn{4}{|c|}{ Akseptor KB Implant } & \multirow{2}{*}{\multicolumn{2}{|c|}{ Jumlah }} & \multirow{3}{*}{$\begin{array}{c}P \\
\text { Value }\end{array}$} & \multirow{3}{*}{$\mathbf{O R}$} \\
\hline & \multicolumn{2}{|c|}{ Ya } & \multicolumn{2}{|c|}{ Tidak } & & & & \\
\hline & f & $\%$ & $\mathbf{f}$ & $\%$ & $\mathbf{f}$ & $\%$ & & \\
\hline $\mathrm{Ya}$ & 42 & 61,8 & 26 & 38,2 & 68 & 100,0 & \multirow{3}{*}{0,000} & \multirow{3}{*}{$\begin{array}{c}45.231 \\
(5.801-352.666)\end{array}$} \\
\hline Tidak & 1 & 3,4 & 28 & 96,6 & 29 & 100,0 & & \\
\hline Jumlah & 43 & & 54 & & 97 & & & \\
\hline
\end{tabular}

Tabel 7 menunjukkan persentase KB Implant lebih tinggi pada ibu yang bekerja dibandingkan ibu yang tidak bekerja $(61,8 \%)$. Hasil uji chi square didapatkan $\mathrm{p}$-value $<\alpha 0,05$, artinya ada hubungan yang bermakna antara pekerjaan ibu dengan Akseptor KB Implant. OR yang didapat yaitu 45.231, artinya ibu yang bekerja mempunyai peluang 9,500 kali menggunakan 
Paula Citra Hakim S, Siti Aisyah dan Eka Afrika, Hubungan Umur, Pendidikan dan Pekerjaan Ibu dengan Akseptor KB Implant di Puskesmas Sri Gunung Kabupaten Musi Banyuasin Tahun 2019

kontrasepsi Implant dibandingkan ibu yang tidak bekerja (OR : 5.801- 352.666).

\section{SIMPULAN}

Dari hasil penelitian yang dilakukan di Puskesmas Sri Gunung Tahun 2019 dapat disimpulkan bahwa :

1. Ada hubungan yang bermakna Umur dengan Akseptor KB Implant di Puskesmas Sri Gunung tahun 2019 dengan $P$ value $=0,000$

2. Ada hubungan yang bermakna pendidikan dengan Akseptor KB Implant di Puskesmas Sri Gunung tahun 2019 dengan $P$ value $=0,000$

3. Ada hubungan yang bermakna Pekerjaan Ibu dengan Akseptor KB Implant di Puskesmas Sri Gunung tahun 2019 dengan $P$ value $=0,000$

\section{DAFTAR PUSTAKA}

Budiman, A. R. (2013). Kapita Selekta Kuesioner. Jakarta: Salemba Medika.

Handayani, S. (2010). Buku ajar pelayanan keluarga berencana. Yogyakarta: Pustaka Rihama, 76.

Kemenkes, R. I. (2017). Data dan informasi profil kesehatan indonesia. Jakarta: Kemenkes RI.

Kusmiwiyati, A. (2018). Pengaruh Penggunaan Alat Bantu Pengambilan Keputusan Ber-KB (ABPK) terhadap Pemilihan Metode Kontrasepsi Jangka Panjang (MKJP). Jurnal Kesehatan Ibu Dan Anak (Mother and Child Medical Science Journal), 3(2), 001-011.

Prawirohardjo, S. (2008). Ilmu kandungan. Jakarta: Yayasan Bina Pustaka Sarwono Prawirohardjo.

Saifuddin, A. B. (2010). Buku Pedoman Praktis Pelayanan Kontrasepsi edisi 2. Jakarta: YBP-SP.

Statistik, B. P., \& BKKBN, K. (2007). Survei demografi kesehatan Indonesia Tahun 2007. Pelayanan kesehatan ibu dan anak.

Suratun, S., Tien, H., \& Rusmiati, S. (2008). Pelayanan keluarga berencana dan pelayanan kontrasepsi. Jakarta: Trans Info Media 